\title{
Challenges Faced by MSICs Operators
}

\author{
Mariam Jamaludin a, Zeenat Begam Yusof ${ }^{b}$ \\ a Faculty of Architecture, Planning and Surveying, \\ Universiti Teknologi MARA, 40000 Shah Alam, Malaysia \\ ${ }^{\mathrm{b}}$ Kulliyyah of Architecture and Environmental Design, \\ International Islamic University Malaysia, 50728 Kuala Lumpur, Malaysia \\ marja67@gmail.com
}

\begin{abstract}
Sustainability becomes main management issues for hospitality firms. Big hospitality firms conduct countless attempts to accommodate into the sustainability agenda. However, the small hospitality firms are left behind. The reason is some challenges that are dragging them. Challenges studies regarding big hospitality companies are plenteous. However, studies regarding challenges of MSIC operators are limited in Malaysia. Therefore, the objectives are to identify the challenges and the rankings. This study is applying the quantitative and qualitative approach. The finding shows that lack of green products is the most salient challenges. In conclusion, this study has managed to identify challenges and provide some recommendations.
\end{abstract}

Keywords: Challenges; Green Practices; Relative Importance Index; Micro and Small Island Chalet

eISSN: 2398-4295 @ 2017. The Authors. Published for AMER ABRA by e-International Publishing House, Ltd., UK. This is an open access article under the CC BY-NC-ND license (http://creativecommons.org/licenses/by-nc-nd/4.0/). Peer-review under responsibility of AMER (Association of Malaysian Environment-Behaviour Researchers), ABRA (Association of Behavioural Researchers on Asians) and cE-Bs (Centre for Environment-Behaviour Studies), Faculty of Architecture, Planning \& Surveying, UniversitiTeknologi MARA, Malaysia.

https://doi.org/10.21834/ajbes.v2i5.44 


\subsection{Introduction}

Green practices are buzzwords for all industries in the world. Industries are pushed to adopt green practices in their operation due to various driving factors and the adverse environmental impacts. Among all the industries, the hospitality industry is also equally involved in this matter. Even though, this industry is not a major contributor to the deterioration of the environment compared to other industries (David, 1995). But, still this it provides significant ecological footprints through the excessive use of the energy, water, and natural resources (Chan, 2011). Therefore, adhering to these externalities, the industry has taken many proactive roles in the environmental conservation and preservation. The hospitality industry has produced formal environmental instruments such as best environmental practices, eco-labels, Environmental Management System (EMSs), environmental performance indicators and green certifications (Ayuso, 2006). Most of the chain-affiliated hotels have started to incorporate environmental instruments in their management and operation.

However, the condition is reversed for the Small-Medium Enterprise (SME) operators. They have small capabilities of financial resources. Small capital hindered them to involved in the corporate environmentalism (Tzschentke, Kirk, \& Lynch, 2008). The financial limitation is one of the challenges identified. However, there are many more challenges. Studies regarding the challenges are very limited especially for SME in Malaysia hospitality firms. Therefore, this study is conducted to fulfill the gap in the literature. The objectives of this study are to determine the challenges faced by the Micro and Small Island Chalets (MSIC) operators and to determine the ranking of the challenges.

\subsection{Literature Review}

Studies regarding challenges of implementing green practices for various industries are a plethora. Some of the examples are: challenges of sustainable facility management in Nigeria by (Ikediashi, Ogunlana, Oladokun, \& Adewuyi, 2013), challenges of organization in implementing green marketing strategies by (Ramirez, 2010), challenges to implementing EMS in organization by (Kirkland \& Thompson, 1999), challenges in adopting EMS by all type of SMEs (C. McKeiver, 2005) and challenges in implementing environmental practices in tourism industry (Chan, 2008; Graci, 2006; Yusof \& Jamaludin, 2014). However, studies regarding challenges faced by SME tourism operators in Malaysia are very limited. Therefore, this study is conducted to recognised the challenges and ranked them into significant and non-significant challenges. Before that, it is very crucial to understand general challenges faced by the SMEs operators. SMEs are the largest business sectors, which generate up to $60 \%$ of the global economic input. Among the five SME sectors in Malaysia, the services sector has the highest distributions of SMEs $(90 \%)$ compared to manufacturing $(5.9 \%)$, agriculture (1\%), construction $(3 \%)$ and mining $(0.1 \%)$ (Corporation, 2011). 
The percentage shows that the numbers of SMEs in the service sector in Malaysia are quite high. The SMEs are known as more 'pollution-intensive' business compared to large business due to the cumulative negative impacts of their operation on the natural environment (Kasim, 2009; Catherine McKeiver \& Gadenne, 2005; Walker, Janice, Lynnaire, Calvin, \& Ute, 2008). Most of the SMEs in Malaysia located in the tourism area, which are highly environmentally sensitive areas such as islands, beaches, forest, and mangrove. There are growing bodies of literature support that the SMEs should engage in environmental management practices due their cumulative negative externalities (Eric S W Chan, 2011; Kasim, 2009). However, most of the studies agreed that SMEs are less likely to have environmental management plans due to the several challenges (Kasim, 2009; Thomas, Shaw, \& Page, 2011; Walker, Janice, Lynnaire, Calvin, \& Ute, 2008; Yacob et al., 2013). Two studies identified SMEs challenges are from two perspectives.

The first perspective is from the owner/manager side. As for the owner/manager side, there is three areas of challenges: (1) characteristics of the SMEs in general, (2) resource availability (financial, human and time) and (3) owner/manager knowledge, interest and motivation. The characteristics of the SMEs, in general, are the first type of challenges, which are pulling them back from being green operators.

According to Hillary (2004) general characteristics of SME is heterogeneous. The examples of heterogeneous characteristics of SMEs are the unique location; runs by independent owner (man or women) of all ages and operators have different education level (McKeiver, 2005). The heterogeneous nature makes it difficult for the government to communicate with the SME regarding the technical and environmental training. The operators usually less actives in any organisation and associations. They run their business based on their knowledge and experiences. Another pertinent characteristic of SMEs is a small size. According to Hillary (2004) small organization, size creates the restriction on the resources and capability to adopt green practices.

The limitations of resources are the second type of challenge. This barrier is related to the limitation of (1) financial capacity, (2) limitation of human resources and (3) time (Hillary, 2004). Commonly, small financial capacity hindered the SME operators to invest in the environmental management plan (Jaafar, Ing, \& Mohd Sukarno, 2011). Often, operators in tourism industry feel that investment in green practices is an additional business investment. The profits gain from the business usually just enough for buying equipment and paying the staffs. Sometimes, owner/manager are not sure that the implementation of green strategies will have a return on their investment (Kasim, 2009).

Regarding human resource, SME operators usually employ less than five staffs, which unlikely have dedicated environmental staffs. Sometimes, the staffs are the family members or local people staying nearby. Islanders on the Malaysian islands have low education level due to the limitation of education facilities on the islands. Therefore, to have staffs that are expert in the environmental practices is impossible. 
The last limitation is time. Tremendous arrivals of tourist at the islands causing the operators busy in entertaining guests compared to engaging in the green practices. Also, to implement green practices in the operation required a longer time frame for the system to be a full function.

The third types of challenges are regarding knowledge, interest and motivations of the owner/manager. Many of the SME operators have lack of knowledge regarding the sustainability practices, the benefits of the environmental improvements, environmental issues and risks posed by their operation due to the low education level and ignorance of the operators (Kasim, 2009). The ignorance of the operators is strongly related to the feeling of unmotivated. The operators feel unmotivated because they have to use their personal capital to invest in green practices, which usually did not give an immediate return (Graci, 2006). So they often pose a question 'what's in it for me'. For them, green practices are the burden for them (Walker et al., 2008).

The second perspective for challenges is from the government or agency side. Challenges identified are (1) lack of communication (2) lack of stakeholder engagement and (3) lack of legislation. Lack of communication between government and SME operators hampered environmental commitment. Most of the time, environmental strategies, best practice, green guidelines only found in papers, seldom reach to the operators. Other than that, lack of information regarding environmental practices benefits, inadequate information regarding environmental programmes and use of very technical or academic language by the government agencies also hindered the SME operators to adopt green practices (Walker et al., 2008).

The second challenge is less engagement from the stakeholder. The SME operators always find that there are little pressure and support from the stakeholder such as the environmental organisation, government, landlord, and guests to implement green strategies (Kasim, 2009)

The third challenge identified is the lack of legislation. The environment legislation exists in most of the countries. However, the enforcement is missing. The enforcement in Malaysia is missing at the State level due to the (1) lack of staffs, (2) lack financial capability, (3) lack of support from the federal government and (4) lack of collaboration between departments and agencies. On the other side, environmental management system, standards, and certifications are only designed for large enterprises not for small enterprises. Therefore, the SME operators, found these standards and certifications are costly to implement and to maintain (Walker et al., 2008).

\section{0 Methodology}

This study employed qualitative and quantitative approach. The data are analysed using descriptive analysis test. The questionnaire was administered by hand to all MSICs owner/manager at the four Marine Park Islands in Malaysia. The islands were Perhentian Kapas, Redang and Tioman Island. MSIC operators randomly selected for interviews. Four operators were interviewed for each island to gain insight of the challenges. 


\subsection{Sample and method of data collection}

The primary method of the study is quantitative analysis. The challenges parameters were prepared through content analysis of few studies such as (Eric S W Chan, 2011; Yusof \& Jamaludin, 2014). The content validity of the questionnaire pretested among the selected academician in International Islamic University Malaysia (IIUM) from Kulliyyah of Architecture and Environmental Design (KAED). The questionnaire consists of two parts. Part 1: Background information of the MSICs and Part 2: 11 challenges parameters. The parameters are:

- Lack of information and knowledge on the green practices

- High implementation and maintenance cost

- Lack of financial capabilities- small size

- Lack of government support

- Lack of government enforcement regarding green practices implementation

- Isolation and transportation problem

- Lack of resources such as freshwater and electricity

- Lack of personnel specially trained staffs in the green practices management

- Lack of support from the owner

- Less support from the tourists on green initiatives

- Lack of green products and suppliers contact in the market

The parameters are tested using five points Likert Scale ranging from $1=$ Strongly Disagree to 5= Strongly Agree. Questionnaires were distributed to 100 operators on the four Marine Park Islands and 85 operators did response. The response rate was $85 \%$, which is quite high. The respondents were owner/manager of the chalets.

The reliability test was conducted to ensure that the measure of the parameters had internal consistency across time and the various parameters measured (Sekaran, 2009). The reliability test conducted. The Cronbach's Alpha (a) score was 0.735 . The score shows that the all the parameters exceed the minimum value of 0.70 (Hair et.al, 2010). Thus, can be concluded that the parameters have the acceptable level of reliability. Significance test also conducted. The probability scores achieved for each variable is $p<0.001$ using Pearson Chi-Square test. Thus, can be concluded that the pattern of the variable score is significant.

\subsection{Limitations}

This study conducted for the Micro and Small Enterprises only. The findings cannot generalise to Medium Enterprises and another sector under the SMEs. This study is not comprehensive because many other islands do not cover in this study due to the time and cost barriers.

\subsection{Respondents' profiles}

The respondents from Tioman Island were 40 operators (46.5\%), Kapas Island was eight 
operators (9.3\%), Perhentian Island was 29 operators (23.8\%) and Redang Island was eight operators (10.5\%). $80 \%$ of the respondents are male, and $20 \%$ are female. $4.7 \%$ of the respondents have primary education level, $70.6 \%$ of the respondents have secondary education level and $24.7 \%$ respondents have the high education level (diploma, certification, and degree). Therefore, the study shows that most of the owner/managers do not have a high education level. $55.3 \%$ of the operators received less than RM 300,000 yearly net income, $32.9 \%$ received between RM 300,000 to RM 1 million and $11.8 \%$ of the operators received more than RM 1 million up to RM 3 million. The finding indicates that most of the operators on the islands are fall under the category of Microenterprises.

\section{0 Results and Discussions}

The descriptive statistics presented in Table 1 showed that lack of green product and supplier contact in the market has the highest mean score (4.58), followed by the isolation and transportation problem (4.55). Next is high implementation and maintenance cost (4.53). Then the lack of trained staffs in green practices management (4.52), lack of information and knowledge on the green practices (4.44) and so on (refer to Table 1- Ranking).

This study indicates that $74.1 \%$ of the MSIC operators strongly agreed that lack of green product and supplier contact in the market were the most significant challenges that are hindering them from implementing environmental practices. The reason is green practices recently introduced in Malaysia, and green products and suppliers limited in Malaysia. Green products easily found in the major cities compared to small islands.

The second highest challenges were isolation and transportation problem. About $72.9 \%$ operators strongly agreed that this factor is a barrier. The MSIC in Malaysia located far from the mainland. It takes about 1-2 hours to reach these islands by ferry or boat. Therefore, it is difficult for the operators to purchase unnecessary goods or equipment due to the high transportation cost. Furthermore, isolation also hindered green knowledge to reach them due to unavailable of the telecommunication system, Internet access, and computer literacy.

Attention grabbing finding from this study is high implementation and maintenance cost is the third challenges, not the first as claimed by many previous studies because few operators on the islands do not agree that implementation and maintenance cost is a barrier. According to them, green practices can be achieved without implementing expensive green strategies but through environmental behaviour (Yusof, Z.B, personal communication, April-June, 2014). Environmental behaviour such as reducing the use of energy, water, and goods can save energy, water and reduce the amount of waste produced.

The fourth highest challenge identified is the lack of trained staffs in green practice management. Micro operators usually have less than five staffs, and sometimes the family members are the staffs. Therefore, to have dedicated environmental officer are not possible. Most of the MSIC operators have the low capital to trained or send their staffs for environmental training and programmes. 
The moderate challenges are the lack of green knowledge, small financial capacity, lack of government support and enforcement. These challenges were discussed in section 2.2. The second last weak barrier identified is the lack of support from the owner (V11). This parameter considered as low barriers because most of the owner/manager is very supportive of the idea of implementing green practices, but they are not entirely ready to implement in their operation.

Whereas, the last barrier is the lack of support from tourists (V12). $50 \%$ of the operators disagreed that there is the lack of support from the tourist. According to them, most of the international tourists are very supportive regarding green practices. They were often involved in beach cleaning programme organised by the operators. Some of them give a big hand to the local people and operators to protect the surrounding environment.

Table 1: Descriptive analysis of the barriers

\begin{tabular}{|c|c|c|c|c|c|}
\hline Veriable & Mean & Median & Mode & Raaking & SD \\
\hline $\begin{array}{l}\text { V1- Lack of information and knowledge on the } \\
\text { grom practices }\end{array}$ & 4.44 & 5.00 & 5 & 5-Moćente & 1.040 \\
\hline V2- High implementatice and malutenance cos! & 4.53 & 5.00 & 5 & 3 - High & .825 \\
\hline $\begin{array}{l}\text { V3- Lack of finmeial capabilisies small capital } \\
\text { V4-Lack of povermment support }\end{array}$ & $\begin{array}{l}4.27 \\
4.39\end{array}$ & $\begin{array}{l}5.00 \\
5.00\end{array}$ & $\begin{array}{l}5 \\
5\end{array}$ & $\begin{array}{l}\text { 7-Mociente } \\
\text { 6-Moderate }\end{array}$ & $\begin{array}{c}1.229 \\
914\end{array}$ \\
\hline $\begin{array}{l}\text { VS-Lack of government enicreernent regandirg } \\
\text { groen practices implementation }\end{array}$ & 4.26 & 5.00 & 5 & 8-Moderate & 836 \\
\hline 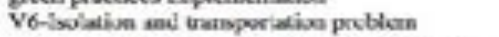 & 4.53 & 5.00 & 5 & 2-High & 919 \\
\hline $\begin{array}{l}\text { V7- Lack of reseurees such as freshwater and } \\
\text { deetricity }\end{array}$ & 3.74 & 4.00 & 5 & $9-10 w$ & 1.320 \\
\hline $\begin{array}{l}\text { V8- Lack of human resources especially trained } \\
\text { staffs in the groen practioes maragernert }\end{array}$ & 4.52 & 5.00 & 5 & 4-High & 934 \\
\hline V9. Lack of support from the owser & 3.14 & 3.00 & 5 & 10-Low & 1.560 \\
\hline $\begin{array}{l}\text { V10-Less suppon from the tourists on geen } \\
\text { isitiatives }\end{array}$ & 2.82 & 3.00 & 5 & 11-Low & 1.373 \\
\hline $\begin{array}{l}\text { V11 Lack of green prodacts and supplicrs } \\
\text { ooetact is the market }\end{array}$ & 4.58 & 5.00 & 5 & 1-High & .850 \\
\hline
\end{tabular}

(Source: Author)

\section{0 Conclusion}

In conclusion, this study has identified the challenges that are hindering the MSIC operators in Malaysia from implementing green practices. This study also has shown different outcome from the previous study. The different outcome is the lack of green product and suppliers are the most significant challenge compared to the Chan (2011) study, which is high implementation and maintenance cost. Therefore, can be concluded that operators in Malaysia are pulled back from applying green products or system in their operation due to the lack of the product itself. Hence, the government needs to take the lead in bringing or introducing more green products and suppliers in the Malaysian market. The authorities need to provide shops near the jetty area, which helps the green suppliers, to sell their green products to the operators. Basic products such as green toiletries, green detergents, biodegradable plastic bags, recycled 
products and much more.

Besides providing the facilities, the government needs to educate the operators. Education regarding environmental practices is very crucial for the operators because of their cumulative negative impacts on the marine environment. They should be informed regarding the barriers, the adverse impacts of their operation, the benefits of being green, funding that they can apply and green products and system available in the market. Support from the government and other stakeholders are crucial for the operators to become green operators. Where else, the operators also should be more open-minded in implementing the green practices in their operation.

\section{Acknowledgement}

This study was funded by IIUM. This study is a part of corresponding author's PhD study at the Universiti Teknologi, Shah Alam Malaysia.

\section{References}

Ayuso, S. (2006). Adoption of Voluntary Environmental Tools for Sustainable Tourism: Analysing the Experience of Spanish Hotel. Corporate Social Responsibility and Environmental Management, 13(4), 207-220.

Chan, E. S. W. (2008). Barriers to EMS in the hotel industry. International Journal of Hospitality Management, 27(2), 187-196. doi:10.1016/j.jclepro.2003.08.006

Chan, E. S. W. (2011). Implementing Environmental management systems in Small and Medium sized hotels: Obstacles. Journal of Hospitality \& Tourism Research, 35(1), 3-23. doi:10.1177/1096348010370857

David, K. (1995). Environmental management in hotels. International Journal of Contemporary Hospitality Management, 7(6), 3-8.

Graci, S. (2006). Accomodating gree: Examining barriers to sustainable tourism development. In TTRA Canada Conference Proceedings. (pp. 15-17). Montebello, Quebec.

Hillary, R. (2004). Environmental management systems and the smaller enterprise. Journal of Cleaner Production, 12(6), 561-569. doi:10.1016/j.jclepro.2003.08.006

Ikediashi, D. I., Ogunlana, S. O., Oladokun, M. G., \& Adewuyi, T. (2013). Assessing the level of commitment and barriers to sustainable facilities management practice: A case of Nigeria. International Journal of Sustainable Built Environment, 1, 167-176. doi:10.1016/j.jjsbe.2013.06.002

Jaafar, M., Ing, T. K., \& Mohd Sukarno, S. Z. (2011). Problems of small and medium budget hotel operators. Special Issue of Tourism \& Hospitality, 12, 73-79.

Kasim, A. (2009). Managerial attitudes towards environmental management among small and medium hotels in Kuala Lumpur. Journal of Sustainable Tourism, 17(6), 709-725. doi:10.1080/09669580902928468 
Kirkland, L.-H., \& Thompson, D. (1999). Challenges in designing, implementing and operating an environmental management system. Business Strategy and the Environment, 8, 128-143.

McKeiver, C. (2005). Environmental Management Systems in Small and Medium Businesses. International Small Business Journal, 23(5), 513-537. doi:10.1177/0266242605055910

Ramirez, E. (2010). Three essays on green marketing strategy. Florida State University.

Tzschentke, N. a., Kirk, D., \& Lynch, P. a. (2008). Going green: Decisional factors in small hospitality operations. International Journal of Hospitality Management, 27(1), 126-133. doi:10.1016/j.ijhm.2007.07.010

Walker, B., Janice, R., Lynnaire, S., Calvin, W., \& Ute, G. (2008). Small and medium enterprises and the environment: barriers, drivers, innovation and best practice. A review of the literature March 2008. Swan Catchment Council.

Yusof, Z. B., \& Jamaludin, M. (2014). Barriers of Malaysian Green Hotels and Resorts. Procedia - Social and Behavioral Sciences, 153, 501-509. doi:10.1016/j.sbspro.2014.10.083 